\title{
Undertreatment of people with major depressive disorder in 21 countries*
}

Graham Thornicroft, Somnath Chatterji, Sara Evans-Lacko, Michael Gruber, Nancy Sampson,

Sergio Aguilar-Gaxiola, Ali Al-Hamzawi, Jordi Alonso, Laura Andrade, Guilherme Borges,

Ronny Bruffaerts, Brendan Bunting, Jose Miguel Caldas de Almeida, Silvia Florescu, Giovanni de Girolamo,

Oye Gureje, Josep Maria Haro, Yanling He, Hristo Hinkov, Elie Karam, Norito Kawakami, Sing Lee,

Fernando Navarro-Mateu, Marina Piazza, Jose Posada-Villa, Yolanda Torres de Galvis and Ronald C. Kessler

\section{Background}

Major depressive disorder (MDD) is a leading cause of disability worldwide.

\begin{abstract}
Aims
To examine the: (a) 12-month prevalence of DSM-IV MDD (b) proportion aware that they have a problem needing treatment and who want care; (c) proportion of the latter receiving treatment; and (d) proportion of such treatment meeting minimal standards.
\end{abstract}

\section{Method}

Representative community household surveys from 21 countries as part of the World Health Organization World Mental Health Surveys.

\section{Results}

Of 51547 respondents, $4.6 \%$ met 12-month criteria for DSM-IV MDD and of these $56.7 \%$ reported needing treatment. Among those who recognised their need for treatment, most (71.1\%) made at least one visit to a service provider. Among those who received treatment, only $41.0 \%$ received treatment that met minimal standards. This resulted in only $16.5 \%$ of all individuals with 12 -month MDD receiving minimally adequate treatment.

\section{Conclusions}

Only a minority of participants with MDD received minimally adequate treatment: 1 in 5 people in high-income and 1 in 27 in low-/lower-middle-income countries. Scaling up care for MDD requires fundamental transformations in community education and outreach, supply of treatment and quality of services.

\section{Declaration of interest}

In the past 3 years, R.C.K. received support for his epidemiological studies from Sanofi Aventis, was a consultant for Johnson \& Johnson Wellness and Prevention and served on an advisory board for the Johnson \& Johnson Services Inc. Lake Nona Life Project. R.C.K. is a co-owner of DataStat Inc. a market research firm that carries out healthcare research.

\section{Copyright and usage}

(c) The Royal college of Psychiatrists 2017.
The Global Burden of Disease 2010 Study indicated that major depressive disorder (MDD) ranked as the second leading cause of years lived with disability in the world and the first to fourth leading cause (out of nearly 300 considered) in each region of the world. ${ }^{1}$ These high estimates are because MDD has both high prevalence (estimated by the Global Burden of Disease 2010 investigators to be the 19th most common disease in the world) ${ }^{1}$ and high severity, and a relatively high proportion of individuals with long illness duration. ${ }^{2-4}$ Only a minority of people with MDD receive any treatment, despite MDD being a leading cause of disability that also significantly worsens the impact of comorbid non-communicable diseases. ${ }^{5,6}$ There is an increasing awareness that MDD can be reliably diagnosed and treated in primary care settings using antidepressant medications and/or brief structured psychological therapies, ${ }^{7}$ but substantial barriers exist to this care being delivered. These include supply-side factors (for example, policies to invest resources, and consequent scarce mental health services, community and human resources), as well as demand-side issues (for example, lack of awareness of MDD as a treatable illness, and stigma and social exclusion associated with lower rates of help-seeking). ${ }^{8,9}$ Substantial economic costs are the consequence both for people with $\mathrm{MDD}^{10}$ and for society, ${ }^{11}$ because of low rates of treatment and recovery. ${ }^{12}$ In this context, the aim of this paper is to present findings from the World Mental

*The paper is submitted on behalf of the World Health Organization World Mental Health Survey collaborators - see the Appendix for details.
Health (WMH) Surveys quantifying: (a) the 12-month prevalence of DSM-IV ${ }^{13}$ MDD in household surveys in 21 countries worldwide; (b) the proportion of those people who are aware that they have a problem serious enough to need treatment and who believe that treatments exist that could help them; (c) the proportion of the latter individuals who actually receive treatment ('contact coverage'); and (d) the proportion of this treatment that meets minimal standards for adequacy.

\section{Method}

\section{Participants}

Data come from the World Health Organization (WHO) WMH surveys, a series of 23 community epidemiological surveys administered in 21 countries. These included 10 countries classified by the World Bank in $2009^{14}$ as low or middle income (Brazil, Bulgaria, Colombia, Iraq, Lebanon, Mexico, Nigeria, Peoples Republic of China (PRC), Peru and Romania) and 11 high income (Argentina, Belgium, France, Germany, Israel, Italy, Japan, Netherlands, Portugal, Spain and the USA). The majority of surveys were based on nationally representative household samples. Three were representative of all urban areas in their countries (Colombia, Mexico, Peru); two were representative of selected regions in their countries (Japan, Nigeria); and four were representative of selected metropolitan areas in their countries (Sao Paulo in Brazil; Medellin in Colombia; Murcia in Spain; Beijing-Shanghai in PRC). 
Trained lay interviewers administered the interviews face to face in the homes of respondents aged 18 years or older and assessed MDD using a fully structured diagnostic interview that produces validated diagnoses of common DSM-IV disorders. ${ }^{13}$ Standardised interviewer training and quality-control procedures were used in each survey. Informed consent was obtained before administering interviews. The institutional review boards of the organisations coordinating the surveys approved and monitored adherence with procedures for informed consent and protecting human participants. Full details of the WMH Survey methodology are available elsewhere. ${ }^{15}$

To reduce respondent burden, the interview was divided into two parts. Part I, which assessed core mental disorders including MDD, was administered to all respondents. Part II, which assessed additional disorders and correlates including service use, was administered to all Part I respondents who met criteria for any Part I disorder plus a probability subsample of other Part I respondents. Part II interviews, the focus of the current report, were weighted by the inverse of their probabilities of selection into Part II and additionally weighted to adjust samples to match population distributions on the crossclassification of key sociodemographic and geographic variables. Further details about WMH sampling and weighting are available elsewhere. $^{15}$

\section{Measures}

\section{Mental disorders}

Mental disorders were assessed with the WHO Composite International Diagnostic Interview (CIDI) Version 3.0, ${ }^{16}$ a fully structured lay-administered interview generating lifetime and 12 -month prevalence estimates of 20 mood, anxiety, behaviour and substance use disorders. The WMH CIDI interview translation, back-translation and harmonisation protocol required culturally competent bilingual clinicians to review, modify and approve key phrases describing symptoms. ${ }^{17}$ However, no attempt was made to go beyond DSM-IV criteria to assess depressionequivalents that might be unique to specific countries. The latter expansion might have led to a change in results, although previous research has shown that the latent structure of major depression is quite consistent across countries. ${ }^{18-20}$ Masked clinical reappraisal interviews with the Structured Clinical Interview for DSM-IV $(\mathrm{SCID})^{21}$ were carried out in four WMH countries. Good concordance was found with diagnoses based on the CIDI. ${ }^{22}$ MDD was defined as meeting lifetime DSM-IV/CIDI criteria for a major depressive episode and not meeting lifetime DSM-IV/ CIDI criteria for broadly defined bipolar disorder (bipolar I-II or subthreshold). As detailed elsewhere, ${ }^{23}$ our definition of subthreshold bipolar disorder includes both hypomania without history of a major depressive episode and subthreshold hypomania with a history of a major depressive episode.

\section{Treatment}

Respondents were asked whether they ever obtained professional treatment for 'problems with their emotions, nerves or use of alcohol or drugs' and, if so, whether they did so in the past 12 months. Those with 12-month treatment were asked whether they saw a mental health specialty treatment provider (psychiatrist, psychologist, other mental health professional in any setting, social worker or counsellor in a mental health specialty treatment setting, used a mental health hotline), general medical treatment provider (primary care doctor, other general medical doctor, any other healthcare profession seen in a general medical setting) or non-medical treatment provider (religious or spiritual advisor, social worker or counsellor, any other type of healer) for a mental health problem. The treatment provider categories offered were the same across countries. A more detailed description of WMH 12 -month treatment measures is presented elsewhere. ${ }^{24}$

The analyses reported here focus on respondents who met DSM-IV criteria for MDD at some time in the 12 months before interview. The definition used of minimally adequate treatment was that of Wang et al, ${ }^{24}$ using evidence-based guidelines ${ }^{25-27}$ that consisted of receiving either pharmacotherapy $(\geqslant 1$ month of a medication, plus $\geqslant 4$ visits to any type of medical doctor) or psychotherapy $(\geqslant 8$ visits with any professional including religious or spiritual advisor, social worker or counsellor). The decision to have four or more physician visits for pharmacotherapy was based on the fact that for medication assessment, initiation and monitoring, four or more visits are generally recommended during the acute and continuation phases of treatment. We required at least eight sessions for psychotherapy based on the fact that clinical trials showing efficacy have generally included eight or more visits. Any respondent in continuing treatment was regarded as having met this definition.

\section{Statistical analyses}

Survey sampling weights were applied in all analyses so that respondents reflected nationally representative samples in terms of sociodemographic characteristics within each country. Standard errors were estimated using the Taylor series linearisation method implemented in the SAS software survey procedures to adjust weighting and clustering. To test for differences between high-income, upper-middle-income, and lower-middle- and low-income country groups, in relation to the key variables of interest related to the aims of the paper, $\chi^{2}$ tests were applied. Statistical significance was evaluated using two-sided 0.05 -level tests.

\section{Results}

The characteristics of the study sites are shown in Table DS1. The weighted average response rate across all countries was $71.2 \%$. A total of 51547 respondents were assessed for 12-month MDD and treatment.

\section{Prevalence rates}

Across all countries, an average of $4.6 \%$ of respondents met 12 -month criteria for DSM-IV/CIDI MDD (Table 1). As in most community epidemiological surveys, MDD prevalence was higher in high-income (5.2\%), than upper-middle-income $(4.7 \%)$ or low-/lower-middleincome $(3.2 \%)$ countries. Given what we know about sample bias, reporting bias and CIDI validity, these are likely conservative estimates.

\section{Recognition of need for treatment}

An average of $56.7 \%$ respondents with 12 -month MDD across surveys reported that they recognised that they needed treatment. It is noteworthy that this recognition is greater in high-income $(64.9 \%)$, than upper-middle-income $(52.2 \%)$ countries and is substantially lower in low-/lower-middle-income countries $(34.6 \%)$. This means that only one out of every three people with depression in low-/lower-middle-income countries recognised a need for treatment.

\section{Obtaining treatment once need is recognised}

Among people with depression who recognised their need for treatment, most $(71.1 \%)$ made at least one visit to some service 


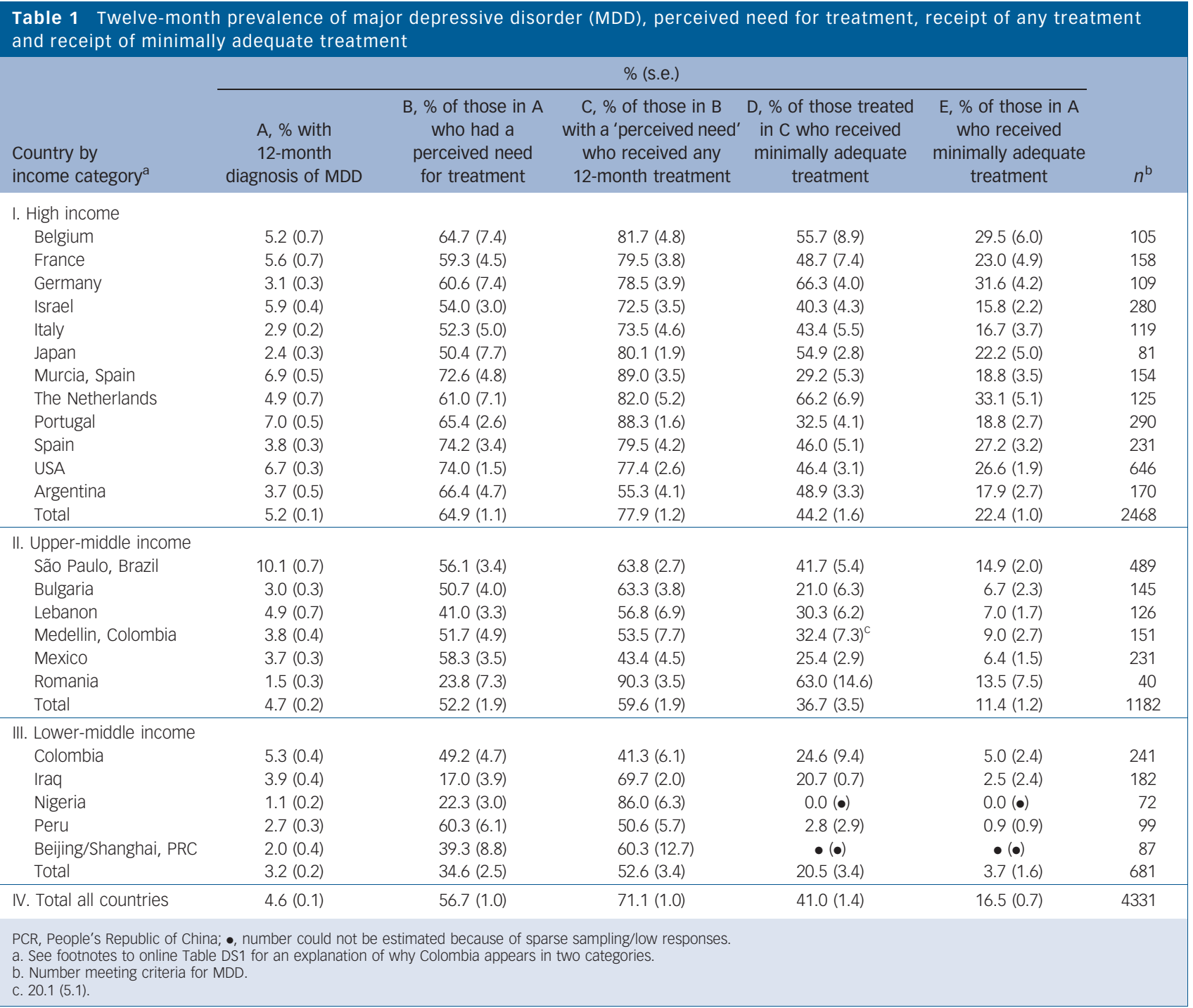

provider for their emotional problems (including visits to religious advisors or traditional healers). Again, there was a gradient, with the treatment proportions being much higher in high-income $(77.9 \%)$, than upper-middle- $(59.6 \%)$, or low-/ lower-middle-income (52.6\%) countries.

\section{Treatment adequacy}

Among patients who received treatment, $41.0 \%$ met criteria for minimally adequate treatment, again with a gradient by country income $(44.2 \%, 36.7 \%$ and $20.5 \%$, respectively in high-, uppermiddle-, and low-/lower-middle-income countries). Among people with MDD (i.e. those who did or did not receive treatment) only $16.5 \%$ received minimally adequate treatment $(22.4 \%, 11.4 \%$ and $3.7 \%$, respectively, in high-, upper-middle-, and low-/lower-middle-income countries).

The results for differences between high-income, uppermiddle-income, and lower-middle- and low-income country groups showed that all countries within an income group were significantly different from other country groups at the $P<0.001$ level for all of the five treatment-related variables shown in Table 1 namely: 12-month prevalence of MDD; perceived need for treatment; any treatment received in 12 months; and the two measures of minimally adequate treatment.

\section{Discussion}

These results show that several different classes of barriers exist to people with MDD receiving minimally adequate treatment and that the combined effect of these barriers is that only a small minority of people with $\mathrm{MDD}$ receive minimally adequate treatment.

\section{Limitations}

Several limitations of this study need to be kept in mind in interpreting these results. The response rates in the WMH surveys varied widely and included some response rates that fell below levels usually considered acceptable. We attempted to control for differential response through post-stratification adjustments, but it remains possible that survey response was related to the presence and severity of mental disorders or treatment in ways that were not corrected.

A second potential limitation is that the reliability and validity of diagnoses made with the WMH CIDI may vary across countries. Although acceptable concordance has been observed between diagnoses made with the CIDI compared with masked clinical re-interviews, such studies have been conducted exclusively in Western countries. It remains possible that the accuracy of CIDI diagnoses could be worse in other countries. 
One distinct possibility is that there may be a lower relevance of CIDI symptom descriptions in non-Western cultures or greater reluctance to disclose or endorse having emotional problems. For example, some people with a major depressive episode might not have experienced this as primarily emotional, and may rather have understood this as disordered sleep or as somatic distress.

Third, without corroborating data on service use we cannot determine the accuracy of self-reported treatment use or how this validity may differ across specific sectors or clinical, sociodemographic and cultural groups. WMH surveys attempted to minimise such inaccuracies by using commitment probes (i.e. questions measuring a participant's commitment to the survey) and excluding respondents who failed to endorse that they would think carefully and answer honestly. Nevertheless, potentially biased recall of service use remains possible and may have led to underestimation of unmet need for treatment. Finally, in spite of the unprecedented scope and size of the WHO WMH survey initiative, some analyses involved small numbers of respondents, leading to imprecision of some estimates.

Fourth, there were diminishing response rates within countries as income increases. As many of the results are discussed in terms of income categories, this is a potential confounding factor for the findings. It is possible that the differences across income categories are actually a reflection of greater selection bias in high-income countries, with participants with greater service use potentially being more likely to respond to the survey.

Fifth, some of these surveys were conducted over a decade ago, and it is possible that treatment rates in these countries may have changed substantially since then. We consider this unlikely however, since periodic data on service provision collected for WHO ATLAS and AIMS purposes shows relatively few such changes over the recent decade.

\section{Implications}

Within these constraints, the results support previous reports in identifying a large 'treatment gap' for people with MDD. ${ }^{28,29}$ Notably the overall prevalence rates of MDD are somewhat greater in high- than in middle- or low-incomes countries, yet all the service utilisation rates are far worse in the low-income settings, namely the perceived need for treatment among people with MDD, and the proportions of people with MDD who receive any, or any minimally adequate treatment. The issue of perceived need for treatment is especially intriguing, as the results show that in overall terms even if acceptable treatment were available to people with MDD, only about a half $(56.7 \%)$ felt that they had a need for treatment, and that this proportion fell to about a third $(34.6 \%)$ in low-/lower-middle-income countries. Previous research shows that this recognition is related to the persistence and severity of depression and is higher among women, the young and people with higher education. ${ }^{30}$ This strongly suggests that efforts to decrease the treatment gap for depression need to address both scaling up the supply of services and supporting people with depression and their family members to recognise that they have the condition and that it is treatable.

Calls for scaling up mental healthcare to date have insufficiently emphasised the quality of services. ${ }^{31}$ Although the criteria used in this study to assess the minimal adequacy of treatment were ad hoc and may need to be refined in future, the results indicate clearly that there are grounds to consider much treatment currently provided to people with MDD ('contact coverage') as falling short of the criteria for evidence-based treatment ('effectiveness coverage'). ${ }^{32}$ One consequence of failing to attend to the quality of care is that this may contribute to low rates of help-seeking if local services for people with mental illness have a poor reputation, and another consequence is likely to be high rates of treatment drop-out before treatment is completed. ${ }^{33}$ Quality improvement initiatives, such as the widespread adoption of the evidence-based WHO mhGAP Intervention Guide, are needed to deal with these problems. ${ }^{7,34,35}$

Providing treatment at the scale required to treat all people with MDD is an imperative, not only for decreasing disability and death by suicide, but also from a moral and human rights perspective. $^{36}$ These WMH survey findings make it clear that success in attacking the problem of unmet need for treatment of people with MDD will require addressing issues at several levels: low rates of recognition of their problem by people with depression, low rates of consultation by people who do recognise that they have such a mental illness, barriers to access treatment ${ }^{37}$ and poor treatment adequacy. Each of these problems requires a distinct intervention, or set of interventions, and all of these interventions are necessary to improve access to quality treatment for people with depression, including e-health and m-health treatment options that may be relevant in low- and middle-income countries. None of these alone will suffice.

The Comprehensive Mental Health Action Plan 2013-2020 adopted by the World Health Assembly ${ }^{38}$ provides the political commitment for these actions, although the human and financial resources deployed within most low- and middle-income countries are still too low to achieve improvement in the provision of treatment for MDD and other mental disorders. In the recently adopted United Nations Sustainable Development Goals, mental health was for the first time explicitly recognised within the concept of Universal Health Coverage. ${ }^{39,40}$ It is clear that providing effective services for people with depression, integrated into general health services, is a vital element of basic healthcare provisions. ${ }^{41}$ As we now have evidence for effective and feasible interventions suitable for low-, middle- and high-income countries, ${ }^{7}$ we call upon national and international organisations to make firm and time-bound commitments to make adequate resources available for scaling up the provision of mental health services so that 'no one is left behind?'

\section{Funding}

The work contained in this paper is carried out in conjunction with the World Health Organization World Mental Health (MMH) Survey Initiative, which is supported by the National Institute of Mental Health (NIMH; R01 MH070884), the John D. and Catherine T. MacArthur Foundation, the Pfizer Foundation, the US Public Health Service (R13MH066849, R01-MH069864, and R01 DA016558), the Fogarty International Center (FIRCA R03-TW006481), the Pan American Health Organization, Eli Lilly and Company, OrthoMcNeil Pharmaceutical, GlaxoSmithKline, Sanofi Aventis and Bristol-Myers Squibb. We thank the staff of the WMH Data Collection and Data Analysis Coordination Centres for assistance with instrumentation, fieldwork and consultation on data analysis. None of the funders had any role in the design, analysis, interpretation of results or preparation of this paper. A complete list of all within-country and cross-national WMH publications can be found at http://www.hcp.med.harvard.edu/wmh/. The Argentina survey - Estudio Argentino de Epidemiología en Salud Mental (EASM) - was supported by a grant from the Argentinian Ministry of Health (Ministerio de Salud de la Nación). The Bulgarian Epidemiological Study of common mental disorders EPIBUL is supported by the Ministry of Health and the National Center for Public Health Protection. The Chinese World Mental Health Survey Initiative is supported by the Pfizer Foundation. The Colombian National Health Survey Initiative is supported by the Pfizer Foundation. The Colombian National
Study of Mental Health (NSMH) is supported by the Ministry of Social Protection. The Study of Mental Health (NSMH) is supported by the Ministry of Social Protection. The
Mental Health Study Medellín - Colombia was carried out and supported jointly by the Center for Excellence on Research in Mental Health (CES University) and the Secretary of Health of Medellin. The ESEMeD project is funded by the European Commission (Contracts QLG5-1999-01042; SANCO 2004123 and EAHC 20081308), (the Piedmont Region (Italy)), Fondo de Investigación Sanitaria, Instituto de Salud Carlos III, Spain (FIS 00/0028), Ministerio de Ciencia y Tecnología, Spain (SAF 2000-158-CE), Departament de Salut, Generalitat de Catalunya, Spain, Instituto de Salud Carlos III (CIBER CB06/02/0046, RETICS RD06/0011 REM-TAP), and other local agencies and by an unrestricted educational grant from GlaxoSmithKline. Implementation of the Iraq Mental Health Survey (IMHS) and data entry were carried out by the staff of the Iraqi $\mathrm{MOH}$ and MOP with direct support from the Iraqi IMHS team with funding from both the Japanese and European Funds through United Nations Development Group Iraq Trust Fund (UNDG ITF). The Israel National Health Survey is funded by the Ministry of Health with support from the Israel National Institute Survey is funded by the Ministry of Health with support from the Israel National Institute
for Health Policy and Health Services Research and the National Insurance Institute of for Health Policy and Health Services Research and the National Insurance Institute of
Israel. The World Mental Health Japan (WMHJ) Survey is supported by the Grant for Research on Psychiatric and Neurological Diseases and Mental Health (H13-SHOGAl-023, 
H14-TOKUBETSU-026, H16-KOKORO-013) from the Japan Ministry of Health, Labour and Welfare. The Lebanese National Mental Health Survey (LEBANON) is supported by the Lebanese Ministry of Public Health, the WHO (Lebanon), National Institute of Health/Fogarty International Center (R03 TW006481-01), Sheikh Hamdan Bin Rashid Al Maktoum Award for Medical Sciences, anonymous private donations to IDRAAC, Lebanon, and unrestricted grants from AstraZeneca, Eli Lilly, GlaxoSmithKline, Hikma Pharmaceuticals, Janssen Cilag, Lundbeck, Novartis and Servier. The Mexican National Comorbidity Survey (MNCS) is supported by The National Institute of Psychiatry Ramon de la Fuente (INPRFMDIES 4280) and by the National Council on Science and Technology (CONACYT-G30544-H), with supplemental support from the PanAmerican Health Organization (PAHO). The Psychiatric Enquiry to General Population in Southeast Spain - Murcia (PEGASUS-Murcia) Project has been financed by the Regional Health Authorities of Murcia (Servicio Murciano de Salud and Consejería de Sanidad y Política Social) and Fundación para la Formación e Investigación Sanitarias (FFIS) of Murcia. The Nigerian Survey of Mental Health and Wellbeing (NSMHW) is supported by the WHO (Geneva), the WHO (Nigeria), and the Federa Ministry of Health, Abuja, Nigeria. The Peruvian World Mental Health Study was funded by the National Institute of Health of the Ministry of Health of Peru. The Portuguese Menta Health Study was carried out by the Department of Mental Health, Faculty of Medica Sciences, NOVA University of Lisbon, with collaboration of the Portuguese Catholic University, and was funded by Champalimaud Foundation, Gulbenkian Foundation, Foundation for Science and Technology (FCT) and Ministry of Health. The Romania WMH Foundation for Science and Technology (FCT) and Ministry of Health. The Romania WMH
study projects 'Policies in Mental Health Area' and 'National Study regarding Mental Health and Services Use' were carried out by National School of Public Health \& Health Service Management (former National Institute for Research \& Development in Health, presen National School of Public Health Management \& Professional Development, Bucharest) with technical support of Metro Media Transilvania, the National Institute of Statistics National Centre for Training in Statistics, SC. Cheyenne Services SRL, Statistics Netherlands and were funded by Ministry of Public Health (former Ministry of Health) with supplemental support of Eli Lilly Romania SRL. The São Paulo Megacity Mental Health Survey is supported by the State of São Paulo Research Foundation (FAPESP) Thematic Project Grant 03/00204-3. The Brazilian National Council for Scientific and Technological Development supports L.A. (CNPq Grant \#307623/2013-0). The US National Comorbidity Survey Replication (NCS-R) is supported by the National Institute of Mental Health (NIMH; U01-MH60220) with supplemental support from the National Institute of Drug Abuse (NIDA), the Substance Abuse and Mental Health Services Administration (SAMHSA), the Robert Wood Johnson Foundation (RWJF; Grant 044708) and the John W. Alden Trust. G.T. is supported by the NaFoundation (RWJF; Grant 044708) and the John W. Alden Trust. G.T. is supported by the Na-
tional Institute for Health Research (NIHR) Collaboration for Leadership in Applied Health Research and Care South London at King's College London Foundation Trust. G.T. is supported by the European Union Seventh Framework Programme (FP7/2007-2013) Emerald project. This paper is an output of the PRogramme for Improving Mental health carE (PRIME). The material has been funded by UK aid from the UK Government, however, the views expressed do not necessarily reflect the UK Government's official policies. The research supported by the National Institute for Health Research (NIHR) Collaboration for research supported by the National Institute for Health Research (NIHR) Collaboration for
Leadership in Applied Health Research and Care South London at King's College London Leadership in Applied Health Research and Care South London at King's College London of the NHS, the NIHR or the Department of Health. The authors acknowledge financia support from the Department of Health via the National Institute for Health Research (NIHR) Biomedical Research Centre and Dementia Unit awarded to South London and Maudsley NHS Foundation Trust in partnership with King's College London and King's College Hospital NHS Foundation Trust. The views expressed in this paper are those of the authors and do not necessarily represent the views or policies of the World Health Organization.

\section{Appendix}

The paper is submitted on behalf of the World Health Organization World Mental Health Survey collaborators: Tomasz Adamowski, PhD, MD, Sergio Aguilar-Gaxiola, MD, PhD, Ali Al-Hamzawi, MD, Mohammad Al-Kaisy, MD, Abdullah Al Subaie, MBBS, FRCP, Jordi Alonso, MD, PhD, Yasmin Altwaijiri, MS, PhD, Laura Helena Andrade, MD, PhD, Lukoye Atwoli, MD, Randy P. Auerbach, PhD, William G. Axinn, PhD, Corina Benjet, PhD, Guilherme Borges, ScD, Robert M. Bossarte, PhD, Evelyn J. Bromet, PhD, Ronny Bruffaerts, PhD, Brendan Bunting, PhD, Ernesto Caffo, MD, Jose Migue Caldas de Almeida, MD, PhD, Graca Cardoso, MD, PhD, Alfredo H. Cia, MD, Stephanie Chardoul, Somnath Chatterji, MD, Alexandre Chiavegatto Filho, PhD, Pim Cuijpers, PhD, Louisa Degenhardt, PhD, Giovanni de Girolamo, MD, Ron de Graaf, MS, PhD, Peter de Jonge, PhD, Koen Demyttenaere, MD, PhD, David D. Ebert, PhD, Sara Evans-Lacko, PhD, John Fayyad, MD, Fabian Fiestas, MD, PhD, Silvia Florescu, MD, PhD Barbara Forresi, PhD, Sandro Galea, DrPH, MD, MPH, Laura Germine, PhD, Stephen E. Gilman, ScD, Dirgha J. Ghimire, PhD, Meyer D. Glantz, $\mathrm{PhD}$, Oye Gureje, PhD, DSc, FRCPsych, Josep Maria Haro, MD, MPH, $\mathrm{PhD}$, Yanling He, MD, Hristo Hinkov, MD, Chi-yi Hu, PhD, MD, Yueqin Huang, MD, MPH, PhD, Aimee Nasser Karam, PhD, Elie G. Karam, MD, Norito Kawakami, MD, DMSc, Ronald C. Kessler, PhD, Andrzej Kiejna, $\mathrm{MD}$, PhD, Karestan C. Koenen, PhD, Viviane Kovess-Masfety, MSC, MD, PhD, Luise Lago, PhD, Carmen Lara, MD, PhD, sing Lee, PhD, Jean-Pierre Lepine, MD, Itzhak Levav, MD, Daphna Levinson, PhD, Zhaorui Liu, MD, $\mathrm{MPH}$, Silvia S. Martins, MD, PhD, Herbert Matschinger, PhD, John J. McGrath, PhD, Katie A. McLaughlin, PhD, Maria Elena Medina-Mora, PhD, Zeina Mneimneh, PhD, MPH, Jacek Moskalewicz, DrPH, Samuel D. Murphy, DrPH, Fernando Navarro-Mateu, MD, PhD, Matthew K. Nock, PhD, Siobhan O'Neill, PhD, Mark Oakley-Browne, MB, ChB, PhD, J. Hans Ormel, PhD, Beth-Ellen Pennell, MA, Marina Piazza, MPH, SCD, Stephanie
Pinder-Amaker, PhD, Patryk Piotrowski, MD, PhD, Jose Posada-Villa, MD, Ayelet M. Ruscio, PhD, Kate M. Scott, PhD, Vicki Shahly, PhD, Derrick Silove, PhD, Tim Slade, PhD, Jordan W. Smoller, SCD, MD, Juan Carlos Stagnaro, MD, PhD, Dan J. Stein, MBA, MSc, PhD, Amy E. Street, PhD, Hisateru Tachimori, PhD, Nezar Taib, MS, Margreet ten Have, PhD, Graham Thornicroft, PhD, Yolanda Torres, MPH, Maria Carmen Viana, MD, PhD, Gemma Vilagut, MS, Elisabeth Wells, PhD, Harvey Whiteford $\mathrm{MD}, \mathrm{MPH}, \mathrm{PhD}$, David R. Williams, MPH, PhD, Michelle A. Williams, SCD, Bogdan Wojtyniak, SCD, Alan M. Zaslavsky, PhD. We are also pleased to acknowledge the comments received on an earlier version of this paper by Dan Chisholm and Shekhar Saxena.

Graham Thornicroft, PhD, Centre for Global Mental Health, Institute of Psychiatry Psychology and Neuroscience, King's College London, UK; Somnath Chatterji, MD, Department of Information, Evidence and Research, World Health Organization, Geneva, Switzerland; Sara Evans-Lacko, PhD, Centre for Global Mental Health, Institute of Psychiatry, Psychology and Neuroscience, King's College London, UK Michael Gruber, MS, Nancy Sampson, BA, Department of Health Care Policy, Harvard Medical School, Boston, Massachusetts, USA; Sergio Aguilar-Gaxiola, MD, PhD, Center for Reduction in Health Disparities, University of California Davis, Sacramento, California, USA; Ali Al-Hamzawi, MD, College of Medicine, Al-Qadisia University, Diwania governorate, Iraq; Jordi Alonso, MD, PhD, Health Services Research Unit, IMIM-Hospital del Mar Medical Research Institute, Barcelona, Spain; Pompeu Fabra University (UPF), Barcelona, Spain; and CIBER en Epidemiología y Salud Pública (CIBERESP), Barcelona, Spain; Laura Andrade, MD, PhD, Section of Psychiatric Epidemiology, LIM-23, Institute of Psychiatry, University of São Paulo Medical School, São Paulo, Brazil; Guilherme Borges, SCD, Instituto Nacional de Psiquiatria, Calzada Mexico Xochimilco No 101, Colonia San Lorenzo Huipulco, Mexico; Ronny Bruffaerts, PhD, Universitair Psychiatrisch Centrum - Katholieke Universiteit Leuven (UPC-KUL), Campus Gasthuisberg, Leuven, Belgium; Brendan Bunting, PhD, Ulster University, Londonderry, Northern Ireland, UK; Jose Miguel Caldas de Almeida, MD, PhD, CEDOC and Department of Mental Health, Nova Medical School/Faculdade Ciências Médicas, Universidade Nova de Lisboa, Lisbon, Portugal; Silvia Florescu, MD, PhD, National School of Public Health Management and Professional Development, Bucharest, Romania; Giovanni de Girolamo, MD, IRCCS St John of God Clinical Research Centre/IRCCS Centro S. Giovanni di Dio Fatebenefratelli, Brescia, Italy; Oye Gureje, MD, PhD, Department of Psychiatry, University College Hospital, Ibadan, Nigeria; Josep Maria Haro, MD, PhD, Parc Sanitari Sant Joan de Déu, Universitat de Barcelona, CIBERSAM, Sant Boi de Llobregat (Barcelona), Spain; Yanling He, MD, Shanghai Mental Health Center, Shanghai Jiao Tong University School of Medicine, Shanghai, China; Hristo Hinkov, MD, National Center for Public Health and Analyses, Sofia, Bulgaria; Elie Karam, MD, Department of Psychiatry and Clinical Psychology, Faculty of Medicine, Balamand University, Beirut, Department of Psychiatry and Clinical Psychology, St George Hospital University Medical Center, Beirut, and Institute for Development Research Advocacy and Applied Care (IDRAAC), Beirut, Lebanon; Norito Kawakami, MD, PhD, Department of Mental Health, School of Public Health, The University of Tokyo, Tokyo, Japan; Sing Lee, PhD, Department of Psychiatry, Chinese University of Hong Kong, Tai Po, Hong Kong; Fernando Navarro-Mateu, MD, PhD, IMIB-Arrixaca, CIBERESPMurcia, Subdirección General de Salud Mental y Asistencia Psiquiátrica, Servicio Murcia, Subdireccion General de Salud Mental y Asistencia Psiquiatrica, Servicio
Murciano de Salud, El Palmar, Murcia, Spain; Marina Piazza, SCD, Universidad Peruana Cayetano Heredia, Instituto Nacional de Salud, Lima, Peru; Jose PosadaVilla, MD, Colegio Mayor de Cundinamarca University, Bogota, Colombia; Yolanda Torres de Galvis, MPH, 'CES University', Center for Excellence on Research in Mental Health, CES University, Medellin, Colombia; Ronald C. Kessler, PhD, Department of Health Care Policy, Harvard Medical School, Boston, Massachusetts, USA

Correspondence: Graham Thornicroft, King's College London, HSR Departmen - Box P029, Institute of Psychiatry, Psychology and Neuroscience, De Crespigny Park, London SE5 8AF, UK. Email: graham.thornicroft@kcl.ac.uk

First received 20 May 2016, final revision 31 Aug 2016, accepted 31 Aug 2016

\section{References}

1 Global Burden of Disease Study 2013 Collaborators. Global, regional, and national incidence, prevalence, and years lived with disability for 301 acute and chronic diseases and injuries in 188 countries, 1990-2013: a systematic analysis for the Global Burden of Disease Study. Lancet 2015; 386: 743-800.

2 Birnbaum HG, Kessler RC, Kelley D, Ben-Hamadi R, Joish VN, Greenberg PE. Employer burden of mild, moderate, and severe major depressive disorder: mental health services utilization and costs, and work performance. Depress Anxiety 2010; 27: 78-89.

3 Li Y, Aggen S, Shi S, Gao J, Li Y, Tao M, et al. Subtypes of major depression: latent class analysis in depressed Han Chinese women. Psychol Med 2014; 44: $3275-88$.

4 van Loo HM, de Jonge P, Romeijn JW, Kessler RC, Schoevers RA. Data-driven subtypes of major depressive disorder: a systematic review. BMC Med 2012; 10: 156.

5 Moussavi S, Chatterij S, Verdes E, Tandon A, Patel V, Ustun B. Depression, chronic diseases, and decrements in health: results from the World Health Surveys. Lancet 2007; 370: 851-8. 
6 Ferrari AJ, Charlson FJ, Norman RE, Patten SB, Freedman G, Murray CJ, et al Burden of depressive disorders by country, sex, age, and year: findings from the global burden of disease study 2010. PLOS Med 2013; 10: e1001547.

7 World Health Organization. mhGAP Intervention Guide for Mental, Neurological and Substance Use Disorders in Non-Specialized Health Settings: Mental Health Gap Action Programme (mhGAP). WHO, 2010.

8 Lasalvia A, Zoppei S, Van Bortel T, Bonetto C, Cristofalo D, Wahlbeck K, et al Global pattern of experienced and anticipated discrimination reported by people with major depressive disorder: a cross-sectional survey. Lancet 2013; 381: 55-62

9 Clement S, Schauman O, Graham T, Maggioni F, Evans-Lacko S, Bezborodovs $\mathrm{N}$, et al. What is the impact of mental health-related stigma on help-seeking? A systematic review of quantitative and qualitative studies. Psychol Med 2015; 45: 11-27.

10 Chisholm D, Diehr P, Knapp M, Patrick D, Treglia M, Simon G. Depression status, medical comorbidity and resource costs. Evidence from an international study of major depression in primary care (LIDO). Br J Psychiatry 2003; 183: 121-31.

11 Kessler RC. The costs of depression. Psychiatr Clin North Am 2012; 35: 1-14

12 Krauth C, Stahmeyer JT, Petersen JJ, Freytag A, Gerlach FM, Gensichen J. Resource utilisation and costs of depressive patients in Germany: results from the primary care monitoring for depressive patients trial. Depress Res Treat 2014; 2014: 730891.

13 American Psychiatric Association. Diagnostic and Statistical Manual of Mental Disorder (4th edn) (DSM-IV). APA, 1994

14 World Bank. World Bank List of Economies. World Bank, 2009 (http:// www.iqla.org/joining/World-Bank_Classification-List_2009.pdf).

15 Heeringa S, Wells E, Hubbard F, Mneimneh Z, Chiu W, Sampson N, et al. Sample designs and sampling procedures. In The WHO World Mental Health Surveys: Global Perspectives on the Epidemiology of Mental Disorders (eds R Kessler, T Ustun): 14-32. Cambridge University Press, 2008.

16 Kessler RC, Ustun TB. The World Mental Health (WMH) Survey Initiative Version of the World Health Organization (WHO) Composite International Diagnostic Interview (CIDI). Int J Methods Psychiatr Res 2004; 13: 93-121.

17 Harkness J, Pennell B, Villar A, Gebler N, Aguilar-Gaxiola S, Bilgen I. Translation procedures and translation assessment in the World Mental Health Survey Initiative. In The WHO World Mental Health Surveys: Global Perspectives on the Epidemiology of Mental Disorders (eds R Kessler, T Ustun): 91-113. Cambridge University Press, 2008.

18 Simon GE, Goldberg DP, von KM, Ustun TB. Understanding cross-national differences in depression prevalence. Psychol Med 2002; 32: 585-94.

19 Bernert S, Matschinger H, Alonso J, Haro JM, Brugha TS, Angermeyer MC, et al. Is it always the same? Variability of depressive symptoms across six European countries. Psychiatry Res 2009; 168: 137-44.

20 Schrier AC, de Wit MA, Rijmen F, Tuinebreijer WC, Verhoeff AP, Kupka RW, et al. Similarity in depressive symptom profile in a population-based study of migrants in the Netherlands. Soc Psychiatry Psychiatr Epidemiol 2010; 45: 941-51

21 First M, Spitzer R, Gibbon M, Williams J. Structured Clinical Interview for DSM-IV Axis I Disorders, Research Version, Non-patient Edition (SCID-I/NP). Biometrics Research, New York State Psychiatric Institute, 2002.

22 Haro JM, Arbabzadeh-Bouchez S, Brugha TS, de Girolamo G, Guyer ME, Jin R, et al. Concordance of the Composite International Diagnostic Interview Version 3.0 (CIDI 3.0) with standardized clinical assessments in the WHO World Mental Health surveys. Int J Methods Psychiatr Res 2006; 15: 167-80.

23 Merikangas KR, Jin R, He JP, Kessler RC, Lee S, Sampson NA, et al. Prevalence and correlates of bipolar spectrum disorder in the world mental health survey initiative. Arch Gen Psychiatry 2011; 68: 241-51.
24 Wang PS, Aguilar-Gaxiola S, Alonso J, Angermeyer MC, Borges G, Bromet EJ, et al. Use of mental health services for anxiety, mood, and substance disorders in 17 countries in the WHO world mental health surveys. Lancet 2007; 370: 841-50.

25 Agency for Health Care Policy and Research. Depression Guideline Panel, Vol 2: Treatment of Major Depression, Clinical Practice Guideline, No 5. US Department of Health and Human Services, Public Health Service, Agency for Health Care Policy and Research, 1993.

26 Lehman AF, Steinwachs DM. Translating research into practice: the Schizophrenia Patient Outcomes Research Team (PORT) treatment recommendations. Schizophr Bull 1998; 24: 1-10.

27 American Psychiatric Association. Practice Guidelines for Treatment of Psychiatric Disorders: Compendium. American Psychiatric Association Press, 2006.

28 Demyttenaere K, Bruffaerts R, Posada-Villa J, Gasquet I, Kovess V, Lepine JP, et al. Prevalence, severity, and unmet need for treatment of mental disorders in the World Health Organization World Mental Health Surveys. JAMA 2004; 291: 2581-90

29 Eaton J, McCay L, Semrau M, Chatterjee S, Baingana F, Araya R, et al. Global Mental Health 4 Scale up of services for mental health in low-income and middle-income countries. Lancet 2011; 378: 1592-603.

30 Kessler RC, Sampson NA, Berglund P, Gruber MJ, Al-Hamzawi A, Andrade L, et al. Anxious and non-anxious major depressive disorder in the World Health Organization World Mental Health Surveys. Epidemiol Psychiatr Sci 2015; 24: 210-26.

31 Eaton J, McCay L, Semrau M, Chatterjee S, Baingana F, Araya R, et al. Scale up of services for mental health in low-income and middle-income countries. Lancet 2011; 378: 1592-603.

32 Da Silva M, Cohen A, Patel V. Evaluations of effectiveness in the real world. In Global Mental Health Trials (eds G Thornicroft, V Patel). Oxford University Press, 2014

33 Wells JE, Browne MO, Aguilar-Gaxiola S, Al-Hamzawi A, Alonso J, Angermeyer $\mathrm{MC}$, et al. Drop out from out-patient mental healthcare in the World Health Organization's World Mental Health Survey initiative. Br J Psychiatry 2013; 202: 42-9.

34 Barbui C, Dua T, Van OM, Yasamy MT, Fleischmann A, Clark N, et al. Challenges in developing evidence-based recommendations using the GRADE approach: the case of mental, neurological, and substance use disorders. PLOS Med 2010; 7: e1000322.

35 Dua T, Barbui C, Clark N, Fleischmann A, Poznyak V, van Ommeren M, et al. Evidence-based guidelines for mental, neurological, and substance use disorders in low- and middle-income countries: summary of WHO recommendations. PLOS Med 2011; 8: e1001122.

36 WHO. Preventing Suicide: A Global Imperative. WHO, 2014.

37 Andrade LH, Alonso J, Mneimneh Z, Wells JE, Al-Hamzawi A, Borges G, et al. Barriers to mental health treatment: results from the WHO World Mental Health surveys. Psychol Med 2014; 44: 1303-17.

38 World Health Organization. Global Mental Health Action Plan 2013-2020. WHO, 2013

39 United Nations. The 2030 Agenda for Global Action and the Sustainable Development Goals. United Nations, 2015.

40 Thornicroft G, Voruba N. Does the United Nations care about mental health? The importance of the sustainable development goals. Lancet Psychiatry 2016; 3: 599-600.

41 Gureje O, Thornicroft G. Health equity and mental health in post-2015 sustainable development goals. Lancet Psychiatry 2015; 2: 12-4. 